\title{
Impact of the association between elevated oestradiol and low testosterone levels on erectile dysfunction severity
}

\begin{abstract}
Ahmed I El-Sakka
Our aim was to assess the impact of the association between elevated oestradiol $\left(E_{2}\right)$ and low testosterone ( $T$ ) levels on erectile dysfunction (ED) severity. A total of 614 male patients with ED and a normal or low $T$ level in association with normal or elevated $E_{2}$ levels were enrolled. Patients underwent routine laboratory investigations in addition to measurements of total $T$, total $E_{2}$, follicle-stimulating hormone (FSH), luteinizing hormone (LH) and prolactin. We compared the responses to the erectile function domain, Q3 (achieving erection) and Q4 (maintaining erection) of the International Index for Erectile Function (IIEF) score in patients with the following: normal $\mathrm{T}$ and $\mathrm{E}_{2}$ levels; low $\mathrm{T}$ level; low $\mathrm{T}$ level and elevated $\mathrm{E}_{2}$ level; and elevated $\mathrm{E}_{2}$ level. Of the patients included, 449 (73.1\%) had normal $T$ and $E_{2}$ levels, 110 (17.9\%) had a low $T$ level, 36 (5.9\%) had a low $T$ level and an elevated $E_{2}$ level, and 19 (3.1\%) had an elevated $E_{2}$ level. Increased ED severity was significantly associated with low $T$ levels, elevated $E_{2}$ levels, and both a low $T$ level and an elevated $E_{2}$ level. Additionally, the mean values of the EF-domain, Q3 and Q4 were significantly lower in patients with both a low $T$ level and an elevated $E_{2}$ level compared to patients with any condition alone. In conclusion, a low $\mathrm{T}$ level had the primary effect on erectile function; however, a concomitantly elevated $\mathrm{E}_{2}$ level had an additive impairment effect.
\end{abstract}

Asian Journal of Andrology (2013) 15, 492-496; doi:10.1038/aja.2013.20; published online 6 May 2013

Keywords: erectile dysfunction (ED); hypogonadism; testosterone; oestradiol

\section{INTRODUCTION}

A diminution in testicular function with a consequence of testosterone $(\mathrm{T})$ depletion is a common occurrence in older men. ${ }^{1,2}$ The multi-factorial mechanisms of this phenomenon, which involve the hypothalamic-pituitary-testicular axis, have been reported. ${ }^{3}$

Several studies have demonstrated that $\mathrm{T}$ has substantial effects on cavernosal tissues and that $\mathrm{T}$ deficiency impairs the anatomic and physiological substrates of erectile capacity that could be partly reversed upon androgen replacement. ${ }^{4,5}$

Oestradiol $\left(\mathrm{E}_{2}\right)$ possesses an opposing functional role of $\mathrm{T}$; therefore, a decline in the $\mathrm{T}$ level will affect its physiological balance with $\mathrm{E}_{2}$ in men. ${ }^{6}$ As a consequence, a high $\mathrm{E}_{2}$ level, which has a strong gonadotropin suppressive effect, may lead to secondary hypogonadism in the ageing male. ${ }^{7}$ Despite the concomitant elevation of $E_{2}$ in hypogonadal men, the information available on the physiological role of $E_{2}$ in erectile function is insufficient to correlate the aetiology of erectile dysfunction (ED) to a high $\mathrm{E}_{2}$ level. ${ }^{8}$ The likelihood of $E_{2}$ affecting the $T$ balance and the independent effect of $E_{2}$ on erectile function have not been well evaluated. ${ }^{9}$ Furthermore, although the association between ED severity and the prospective decrease in testosterone has been investigated, ${ }^{10}$ the impact of an elevated $\mathrm{E}_{2}$ level on ED severity has not been well addressed. The current study was designed to assess the impact of an association between an elevated $\mathrm{E}_{2}$ level and a low $\mathrm{T}$ level on ED severity.

\section{MATERIALS AND METHODS}

Research design

This was a prospective office-based study. From January 2009 to December 2010, 614 male patients with a clinical diagnosis of ED associated with normal or low $\mathrm{T}$ and/or elevated $\mathrm{E}_{2}$ levels who visited our andrology clinic were enrolled in this study.

\section{ED assessment}

Patients were screened for ED using the International Index for Erectile Function (IIEF). ${ }^{11}$ The erectile function domain consists of questions $1-5$ and question 15 for assessing the global erectile function. These questions were used to measure items regarding ability to obtain an erection, the hardness of the erection, penetration ability, ability to maintain an erection, difficulty maintaining an erection until the end of intercourse and erection confidence. In the current study, we did not investigate the internal consistency of the IIEF scale or subscales; however, previous studies in different languages have demonstrated that the intraclass correlation coefficients (test-retest reproducibility) of the IIEF scale and subscales are significantly high. Cronbach's alpha coefficient has also indicated a high internal consistency. ${ }^{12,13}$ Scoring the IIEF domain of erectile function allowed the classification of each patient as having no (26-30), mild (17-25), moderate (11-16) or severe (0-10) ED. At the same visits during which they were assessed for ED, all patients were also interviewed to gather their sociodemographic characteristics and relevant medical 
history. We compared the responses to the erectile function domain, Q3 (achieving erection), Q4 (maintaining erection) and ED duration in patients with (i) normal $\mathrm{T}$ and $\mathrm{E}_{2}$ levels, (i) a low $\mathrm{T}$ level with a normal $\mathrm{E}_{2}$ level, (iii) a low $\mathrm{T}$ level and an elevated $\mathrm{E}_{2}$ level and (iv) an elevated $\mathrm{E}_{2}$ level with a normal $\mathrm{T}$ level. Patients gave informed consent to be included in the study. The study was approved by the Institutional Review Board.

\section{Laboratory assessment}

Patients underwent routine laboratory investigations in addition to evaluations of total $\mathrm{T}$, total $\mathrm{E}_{2}$, follicle-stimulating hormone ( $\mathrm{FSH}$ ), luteinizing hormone ( $\mathrm{LH})$ and prolactin.

Total $\mathrm{T}$, total $\mathrm{E}_{2}, \mathrm{FSH}, \mathrm{LH}$ and prolactin were assessed using electrochemiluminescence immunoassays according to the manufacturer's instructions (Elecsys Systems 20/10; Roche Diagnostics Corporation, Indianapolis, IN, USA). The target values and ranges were determined and obtained using the Elecsys assay reagents and analysers available at the time. The measurement range $(0.025-$ $15.0 \mathrm{ng} \mathrm{ml}^{-1}$ or $0.087-52.0 \mathrm{nmol} \mathrm{l^{-1 }}$ ) was defined by the limit of detection and the maximum of the master curve. The interassay coefficient of variation for total $\mathrm{T}$ at concentrations of $24-700 \mathrm{ng} \mathrm{dl}^{-1}$ $\left(0.83-24.31 \mathrm{nmoll}^{-1}\right)$ was $7.4 \%-1.7 \%$. Elecsys PreciControl Universal 1 and 2 were used for quality control; these reagents contain lyophilised control serum based on human serum in two concentration ranges. The controls were used to monitor the accuracy and precision of the Elecsys immunoassays.

\section{Definitions}

Body mass index (BMI, $\mathrm{kg} \mathrm{m}^{-2}$ ) was rated as follows: normal $(<25)$, overweight $(25-<30)$ and obese $(\geqslant 30)$.
Low $\mathrm{T}$ was rated as total testosterone measuring $<2.8(2.8-8.8) \mathrm{ng} \mathrm{ml}^{-1}$ on three morning (8:00-11:00 a.m.) occasions (specimens were assayed individually, and the results were averaged).

High $\mathrm{E}_{2}$ was considered total $\mathrm{E}_{2}>42.6(7.6-42.6) \mathrm{pg} \mathrm{ml}^{-1}$.

Prolactin (4.1-20 ng ml ${ }^{-1}$ ); FSH (1.5-12.4 $\mathrm{mIU} \mathrm{ml}^{-1}$ ); LH (1.7$8.6 \mathrm{mIU} \mathrm{ml}^{-1}$ )

A normal hormonal pattern was considered to be a normal level of both total testosterone and $\mathrm{E}_{2}$.

\section{Data analysis}

The data were analysed using the Statistical Package for the Social Sciences (SPSS.14.0) software programme (SPSS, Inc., Chicago, IL, USA). The chi-square test was used to compare categorical variables, including sociodemographics, medical comorbidities, ED severity and $\mathrm{ED}$ duration according to the four categories of $\mathrm{T}$ and $E_{2}$ patterns (Tables 1 and 2). An unpaired t-test and oneway ANOVA were used to compare the mean values of the erectile function domain, Q3 and Q4 according to the four categories of T and $\mathrm{E}_{2}$ patterns (Tables 2 and 3 ).

\section{RESULTS}

Sociodemographics and characteristics of the study population A total of 614 male patients were included in this study. Of the patients, $449(73.1 \%)$ had normal $\mathrm{T}$ and $\mathrm{E}_{2}$ levels, 110 (17.9\%) had a low $\mathrm{T}$ level, $36(5.9 \%)$ had a low $\mathrm{T}$ level and an elevated $\mathrm{E}_{2}$ level and $19(3.1 \%)$ had an elevated $\mathrm{E}_{2}$ level. The mean age and standard deviation of the study sample was $56.6 \pm 11.4$ years, and $36.6 \%$ were less than 50 years of age. Additionally, $78.7 \%$ were overweight or obese, and $29.5 \%$ were current or ex-smokers. The majority of patients (78.8\%) had one or more risk factors or medical comorbidities (diabetes, hypertension, dyslipidaemia, ischaemic heart disease) (Table 1).

Table 1 Distribution of sociodemographic characteristics and medical co-morbidities in the study population according to hormonal pattern

\begin{tabular}{|c|c|c|c|c|c|}
\hline \multirow{2}{*}{$\begin{array}{l}\text { Sociodemog. and medical } \\
\text { comorbidities }\end{array}$} & \multicolumn{4}{|c|}{ Pattern of hormones $(N=614)$} & \multirow{2}{*}{$P$} \\
\hline & Normal $(N=449)$ & $\operatorname{Low} T(N=110)$ & $\operatorname{High~}_{2}(N=19)$ & Low $T+$ high $E_{2}(N=36)$ & \\
\hline \multicolumn{6}{|l|}{ Age groups } \\
\hline$<50$ years & $196(43.7 \%)$ & $16(14.5 \%)$ & $8(42.1 \%)$ & $5(13.9 \%)$ & ${ }^{1} P=0.001,{ }^{2} P=0.001$ \\
\hline$\geqslant 50$ years & $253(56.3 \%)$ & $94(85.5 \%)$ & $11(57.9 \%)$ & $31(86.1 \%)$ & $\begin{array}{l}{ }^{3} P>0.05,{ }^{4} P=0.001 \\
{ }^{5} P=0.001,{ }^{6} P>0.05\end{array}$ \\
\hline \multicolumn{6}{|r|}{ 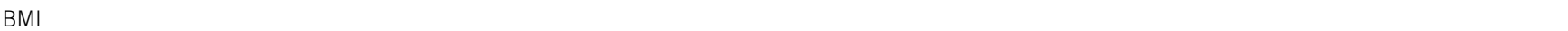 } \\
\hline$<25$ & $87(19.4 \%)$ & $12(10.9 \%)$ & $2(10.5 \%)$ & $3(8.3 \%)$ & ${ }^{1} P>0.05,{ }^{2} P=0.001$ \\
\hline $25-<30$ & $99(22 \%)$ & $24(21.8 \%)$ & $4(21 \%)$ & $4(11.1 \%)$ & ${ }^{3} P>0.05,{ }^{4} P>0.05$ \\
\hline$\geqslant 30$ & $263(58.6 \%)$ & $74(67.3 \%)$ & $13(68.4 \%)$ & $29(80.6 \%)$ & ${ }^{5} P>0.05,{ }^{6} P>0.05$ \\
\hline \multicolumn{6}{|l|}{ Smoking } \\
\hline None & $323(72 \%)$ & $74(67.3 \%)$ & $13(68.4 \%)$ & $23(63.9 \%)$ & ${ }^{1} P>0.05,{ }^{2} P=0.02$ \\
\hline Ex-smoker & $45(10 \%)$ & $14(12.7 \%)$ & $2(10.5 \%)$ & $5(13.9 \%)$ & ${ }^{3} P>0.05,{ }^{4} P>0.05$ \\
\hline Current & $81(18 \%)$ & $22(20 \%)$ & $4(21 \%)$ & $8(22.2 \%)$ & ${ }^{5} P>0.05,{ }^{6} P>0.05$ \\
\hline \multicolumn{6}{|l|}{ Number of comorbidity } \\
\hline One or more & $337(75.1 \%)$ & $98(89.1 \%)$ & $16(84.2 \%)$ & $33(91.7 \%)$ & ${ }^{1} P=0.01,{ }^{2} P=0.001$ \\
\hline None & $112(24.9 \%)$ & $12(10.9 \%)$ & $3(15.8 \%)$ & $3(8.3 \%)$ & ${ }^{3} P=0.04,{ }^{4} P=0.02$ \\
\hline & & & & & ${ }^{5} P=0.008,{ }^{6} P=0.01$ \\
\hline
\end{tabular}

Abbreviations: BMI, body mass index; T, testosterone; $E_{2}$, oestradiol; sociodemog., sociodemographic.

The chi-square $\left(\chi^{2}\right)$ test was used to compare the non-parametric variables of sociodemographics and medical comorbidities according to the pattern of the testosterone and oestradiol levels at $P<0.05$.

${ }^{1} P=$ normal vs. low $T$.

${ }^{2} P=$ normal vs. low $\mathrm{T}+$ high $\mathrm{E}_{2}$.

${ }^{3} P=$ low $T$ vs. low $\mathrm{T}+$ high $\mathrm{E}_{2}$.

${ }^{4} P=$ low $T$ vs. high $\mathrm{E}_{2}$.

${ }^{5} P=$ low $\mathrm{T}+$ high $\mathrm{E}_{2}$ vs. high $\mathrm{E}_{2}$.

${ }^{6} P=$ normal vs. high $\mathrm{E}_{2}$. 
Table 2 Distribution of ED severity and duration, erectile function domain, Q3 and Q4 according to hormonal pattern

\begin{tabular}{|c|c|c|c|c|c|}
\hline \multirow{2}{*}{ ED variables } & \multicolumn{4}{|c|}{ Pattern of hormones $(N=614)$} & \multirow{2}{*}{$P$} \\
\hline & Normal $(N=449)$ & $\operatorname{Low} T(N=110)$ & $\operatorname{High} E_{2}(N=19)$ & Low $T+$ high $E_{2}(N=36)$ & \\
\hline \multicolumn{6}{|l|}{ ED severity } \\
\hline Moderate & $247(55 \%)$ & $45(40.9 \%)$ & $9(47.4 \%)$ & $8(22.2 \%)$ & ${ }^{3} P=0.02,{ }^{4} P>0.05$ \\
\hline Severe & $111(24.7 \%)$ & $54(49.1 \%)$ & $7(36.8 \%)$ & $26(72.2 \%)$ & ${ }^{5} P=0.001,{ }^{6} P=0.02$ \\
\hline ED duration & & & & & ${ }^{1} P>0.05,{ }^{2} P>0.05$ \\
\hline EF-domain (mean \pm s.d.) & $15.2 \pm 4.1$ & $11.4 \pm 4.6$ & $12.2 \pm 3.6$ & $7.7 \pm 3.2$ & $\begin{array}{l}{ }_{1} P=0.001,{ }^{2} P=0.001 \\
{ }^{3} P=0.01,{ }^{4} P>0.05 \\
{ }^{5} P=0.001,{ }^{6} P=0.01\end{array}$ \\
\hline Q3 (mean \pm s.d.) & $2.4 \pm 0.88$ & $1.9 \pm 0.71$ & $2.1 \pm 0.71$ & $1.4 \pm 0.61$ & $\begin{array}{l}{ }^{1} P=0.001,{ }^{2} P=0.001 \\
{ }^{3} P=0.01,{ }^{4} P>0.05 \\
{ }^{5} P=0.001,{ }^{6} P=0.01\end{array}$ \\
\hline
\end{tabular}

Abbreviations: BMI, body mass index; $E_{2}$, oestradiol; T, testosterone.

The chi-square $\left(\chi^{2}\right)$ test was used to compare the non-parametric variables of ED severity and duration according to the pattern of the testosterone and oestradiol levels. An unpaired $t$-test and one-way ANOVA were used to compare the mean values of the EF-domain and Q3 according to the pattern of the testosterone and oestradiol levels. Significance was set at $P<0.05$.

${ }^{1} P=$ normal vs. low $T$.

${ }^{2} P=$ normal vs. low $\mathrm{T}+$ high $\mathrm{E}_{2}$.

${ }^{3} P=$ low $T$ vs. low $T+$ high $E_{2}$.

${ }^{4} P=$ low $T$ vs. high $E_{2}$.

${ }^{5} P=$ low $\mathrm{T}+$ high $\mathrm{E}_{2}$ vs. high $\mathrm{E}_{2}$.

${ }^{6} P=$ normal vs. high $E_{2}$.

\section{Risk factors in the study population}

A normal hormonal pattern was identified in $87.1 \%(196 / 225)$ of patients less than 50 years of age and $86.2 \%(112 / 130)$ of patients with no risk factors. Patients with a normal hormonal pattern had a significantly lower BMI and were less likely to smoke in comparison to patients with a low $\mathrm{T}$ level and high $\mathrm{E}_{2}$ level $(P<0.05$ for each) (Table 1). Age, obesity, smoking and medical comorbidities did not significantly differ among patients with low $\mathrm{T}$ alone and patients with both a low $\mathrm{T}$ level and an elevated $\mathrm{E}_{2}$ level ( $P>0.05$ for each) (Table 1).

\section{Hormonal pattern and ED}

Increased ED severity was significantly associated with a low T level, an elevated $\mathrm{E}_{2}$ level, and both a low $\mathrm{T}$ level and an elevated $\mathrm{E}_{2}$ level
( $P<0.05$ for each) (Tables 2 and 3). No significant association was observed between hormonal abnormalities and ED duration $(P>0.05$ for each) (Table 2). The mean values of the EF-domain, Q3 and Q4 were significantly lower in patients with both a low $\mathrm{T}$ level and an elevated $\mathrm{E}_{2}$ level compared to patients with any of the conditions alone $(P<0.05$ for each) (Table 2). Patients with low T only had significantly lower mean values of the EF-domain, Q3 and Q4 compared to patients with a normal hormonal pattern $(P<0.05$ for each) (Table 2). No significant differences in the mean values of the EF-domain, Q3 and Q4 were observed between patients with low $\mathrm{T}$ and patients with elevated $\mathrm{E}_{2}$ levels ( $P>0.05$ for each) (Table 2$)$. ED severity was not significantly associated with high level of $\mathrm{FSH}, \mathrm{LH}$, prolactin or the lipid profile in the study population ( $P>0.05$ for each) (Table 3 ).

Table 3 Mean hormone levels according to ED severity

\begin{tabular}{lccc}
\hline & \multicolumn{3}{c}{ ED severity } \\
\cline { 2 - 3 } Continuously coded variables & Mild and moderate (mean \pm s.d.) & Severe (mean \pm s.d.) \\
\hline Hormones & & & \\
$\quad$ Testosterone & $4.6 \pm 2.5$ & $3.2 \pm 1.9$ & 0.001 \\
Oestradiol & $29.8 \pm 8.5$ & $38.4 \pm 9.3$ & 0.02 \\
Prolactin & $10.3 \pm 4.3$ & $11.7 \pm 5.1$ & $>0.05$ \\
FSH & $7.7 \pm 3.4$ & $8.2 \pm 4.1$ & $>0.05$ \\
LH & $6.5 \pm 2.9$ & $6.7 \pm 2.8$ & $>0.05$ \\
Dyslipidaemia & & & $>0.05$ \\
Cholesterol & $189.4 \pm 40.1$ & $191.1 \pm 42.6$ & $>0.05$ \\
Triglyceride & $172.3 \pm 86.4$ & $176.5 \pm 94.3$ & $>0.05$ \\
LDL & $117.6 \pm 42.9$ & $119.2 \pm 45.1$ & $>0.05$ \\
HDL & $42.1 \pm 13.4$ & $41.3 \pm 11.4$ & \\
\hline
\end{tabular}

Abbreviations: ED, erectile dysfunction; FSH, follicle-stimulating hormone; HDL, high density lipoprotein; LH, luteinizing hormone; LDL, low density lipoprotein; SHBG, sex hormone binding globulin.

An unpaired $t$-test was used to compare mean values of testosterone, oestradiol, prolactin, FSH, LH and SHBG in patients with mild and moderate ED versus severe ED. Significance was set at $P<0.05$. 


\section{DISCUSSION}

In this study, we assessed the impact of low $\mathrm{T}$ level and elevated $\mathrm{E}_{2}$ level individually and together on ED severity. We demonstrated that both low $\mathrm{T}$ level and elevated $\mathrm{E}_{2}$ level had a negative impact on erectile function and were associated with increased ED severity. No significant associations between hormonal abnormalities and ED duration were observed. The Massachusetts Male Aging Study reported a prevalence of $20 \%$ for hypogonadism in men older than 55 years of age when total $\mathrm{T}$ levels were lower than normal for young healthy subjects. ${ }^{14}$ In the current study, we found that $23.8 \%$ of patients had low T only or low $\mathrm{T}$ in addition to elevated $\mathrm{E}_{2}$. The mechanisms behind the ageing-associated decrease in androgen level and the decrease patients with ED have not been fully elucidated. In a previous study, we demonstrated the yearly pattern of $\mathrm{T}$ depletion in patients with ED. ${ }^{10}$ Furthermore, the possibility of decreased testicular function in older men has been reported to result from several factors, including a disturbance in the hypothalamic-pituitary-testicular axis. ${ }^{3}$

Oestrogens are generally considered as female hormones. However, data obtained from more recent studies have noted the role of oestrogens in male reproduction, which in the past, was a concept confined only to female reproduction. ${ }^{15}$ The pathophysiological consequences of elevated $\mathrm{E}_{2}$ in males have recently gained interest. Oestrogen has been reported to have a significantly negative effect on sexual behaviour and ultimately results in decreased intracavernosal pressure and nitric oxide-mediated cavernosal smooth muscle relaxation. ${ }^{16,17}$ In addition, the action of $E_{2}$ through a non-genomic mechanism has been reported in which $\mathrm{E}_{2}$ can modulate the cell surface and influence ionic channels as a part of the tissue response. ${ }^{18}$ Although the elevated $\mathrm{E}_{2}$ levels in ageing males may act as a risk factor for $\mathrm{ED},{ }^{9}$ the causeeffect relationship is still unknown. ${ }^{19}$

A recent large population-based study showed that total and free $\mathrm{T}$, but not $\mathrm{E}_{2}$ or dihydrotestosterone (DHT), was associated with overall sexual function in middle-aged and older men. $\mathrm{E}_{2}$ was the only hormone associated with sexual function-related distress, such that higher levels were related to greater distress. ${ }^{20}$ Although several interesting studies have elucidated the role of $E_{2}$ in male reproduction, data on the peripheral levels of sex steroids are lacking. Huhtaniemi et al. ${ }^{21}$ reported that increased oestrogen activity rather than decreased androgen activity is associated with longer androgen receptor CAG repeats. Furthermore, Saltiki et al. ${ }^{22}$ investigated the effect of oestrogen levels on endothelial function in males and concluded that endogenous oestrogen levels were associated with flow-mediated dilatation, independent of age and lipid levels, showing a protective effect in middle-aged male subjects.

Although androgen and $\mathrm{E}_{2}$ are physiological antagonists in many organs, the impact of $\mathrm{E}_{2}$ on the $\mathrm{T}$ balance is unclear; therefore, $\mathrm{ED}$ in the elderly may result from a pathophysiological $\mathrm{E}_{2}-\mathrm{T}$ imbalance. ${ }^{23}$ This hormonal imbalance in the elderly can be attributed, at least in part, to modifiable para-aging phenomena. In the present study, there was a significant increase in BMI in patients with both low $\mathrm{T}$ and high $\mathrm{E}_{2}$. Age, obesity, smoking and medical co-morbidities were not significantly different among patients with low $\mathrm{T}$ alone and patients with both a low $\mathrm{T}$ level and an elevated $\mathrm{E}_{2}$ level. This finding is consistent with previous studies showing a complex relationship between ED and hormonal imbalance in obese patients. Furthermore, associations of obesity and its negative correlation with leptin level and androgen insensitivity have been reported. ${ }^{9,24,25}$ With increasing BMI, waist circumference and per cent body fat, another study showed that total and free testosterone and sex hormone-binding globulin concentrations decreased, while total and free $\mathrm{E}_{2}$ increased. The magnitudes of the changes of these hormones were similar, with a one-quartile increase in each body fat measure. ${ }^{26}$ In addition to the hormonal imbalance that can occur with ageing, type 2 diabetes, obesity, hypercholesterolaemia and cardiovascular disease, some of these clinical states are known risk factors for ED. A more recent study demonstrated that the calculated free $\mathrm{E}_{2}$ concentration in men with a subnormal free $\mathrm{T}$ concentration was lower than that in men with a normal free $\mathrm{T}$ concentration. Directly measured free $\mathrm{E}_{2}$ concentrations were also lower in men with subnormal free testosterone concentrations. ${ }^{27}$ The suppression of the hypothalamic-pituitary-gonadal axis in patients with subnormal free $\mathrm{T}$ concentrations and type 2 diabetes has not been associated with increased $\mathrm{E}_{2}$ concentrations. ${ }^{27}$

In the current study, low $\mathrm{T}$ and/or elevated $\mathrm{E}_{2}$ levels were associated with increased ED severity. A low T level caused the primary effect; however, the existence of a concomitantly elevated $\mathrm{E}_{2}$ level increased the severity of ED. A previous study has demonstrated that an $E_{2}-T$ imbalance and relative elevation of $\mathrm{E}_{2}$ may play a role in the causation and perpetuation of ED. Testosterone supplements improve sexual function in patients with hypogonadism. However, the value of $\mathrm{T}$ supplementation, which may be aromatised to $E_{2}$ in men with possible hyperoestrogenism, is questionable. ${ }^{28} \mathrm{~A}$ more recent review of the literature demonstrated that the current evidence does not support a role of naturally occurring oestrogen elevations in testosterone deficiency or the treatment of elevated oestrogens during testosterone therapy. ${ }^{29}$ Empirical clomiphene citrate (anti-estrogen) was shown to improve sexual function in a group of ED patients with hypogonadism. ${ }^{30}$ Although the aromatase inhibitor anastrozole increased both bioavailable and total $\mathrm{T}$ and reduced $\mathrm{E}_{2}$, there was no concurrent improvement in the IIEF scores, indicating the importance of other coexistent factors. $^{31}$

Previous studies have reported the importance of the $\mathrm{E}_{2} / \mathrm{T}$ ratio. However, in the current study, we addressed the impacts of the absolute value of each individually and together on ED severity. Extrapolating those findings could raise several clinically relevant issues, including whether an $\mathrm{E}_{2}$ assay may eventually find a place in the routine clinical investigation of $\mathrm{ED}$. The $\mathrm{E}_{2} / \mathrm{T}$ ratio may be a useful diagnostic marker for hormonal abnormalities in ED patients and for hormone follow-up through appropriate therapeutic titration.

Although the Elecsys system and the electrochemiluminescence immunoassay might not currently be the state of the art for measuring steroid levels, they are capable of distinguishing eugonadal males from hypogonadal males if adult male reference ranges have been established in each individual laboratory, and they have been reported to accurately identify low $\mathrm{T}$ levels in men. ${ }^{32}$

A potential methodological limitation of our study is the relatively small number of patients in some categories of hormonal abnormalities. Age, obesity, smoking and medical comorbidities did not significantly differ among patients with low $\mathrm{T}$ alone and patients with both a low $\mathrm{T}$ level and an elevated $\mathrm{E}_{2}$ level, which suggests that they had little effect on the difference in ED severity between groups. However, the exclusive influence of those possible confounders on each category of hormonal pattern was not addressed in the present study and will be considered in future studies.

The subjects and standard instruments we used indicate that our findings are reliable and certainly signify a good base for further studies. Additional studies with a larger sample size are needed to investigate how much both low $\mathrm{T}$ and high $\mathrm{E}_{2}$ affect the pathogenesis of $\mathrm{ED}$, particularly the vascular, cavernosal smooth muscle and neuronal mechanisms of erection. Future research should also investigate other unclear issues, including how low $\mathrm{T}$ and high $\mathrm{E}_{2}$ influence each other 
and whether the normal male ageing process is responsible for the pathophysiology of ED in association with both hormonal abnormalities. Future studies should also examine the presence of concurrent organic conditions and medical comorbidities that predispose individuals to similar hormonal derangements that may ultimately affect successful management outcomes.

\section{Conclusion}

Low $\mathrm{T}$ and elevated $\mathrm{E}_{2}$ levels are associated with increase ED severity when present individually or concomitantly. A low T level demonstrated the principal effect; however, the existence of a concomitantly elevated $\mathrm{E}_{2}$ level increased the severity of $\mathrm{ED}$ in patients with a low $\mathrm{T}$ level.

\section{COMPETING FINANCIAL INTERESTS}

All authors declare that there are no competing financial interests.

1 Morales A. An integral view of the neuroendocrine aspects of male sexual dysfunction and aging. Can J Urol 2003; 10: 1777-9.

2 Gray A, Berlin JA, McKinlay JB, Longcope C. An examination of research design effects on the association of testosterone and male aging: results of a meta-analysis. J Clin Epidemiol 1991; 44: 671-84.

3 Vermeulen A, Kaufman JM. Aging of the hypothalamopituitary-testicular axis in men. Horm Res 1995; 43: 25-8.

4 Gooren LJ, Saad F. Recent insights into androgen action on the anatomical and physiological substrate of penile erection. Asian J Androl 2006; 8: 3-9.

5 Traish AM, Goldstein I, Kim NN. Testosterone and erectile function: from basic research to a new clinical paradigm for managing men with androgen insufficiency and erectile dysfunction. Eur Urol 2007; 52: 54-70.

6 Sharpe RM. Do males rely on female hormones? Nature 1997; 390: 447-8.

7 Cohen PG. The role of estradiol in the maintenance of secondary hypogonadism in males in erectile dysfunction. Med Hypotheses 1998; 50: 331-3.

8 Srilatha B, Adaikan PG. Oestrogen-androgen crosstalk in the pathophysiology of erectile dysfunction. Asian J Androl 2003; 5: 307-13.

9 Srilatha B, Adaikan PG, Chong YS. Relevance of oestradiol testosterone balance in erectile dysfunction patients' prognosis. Singapore Med J 2007; 48: 114-8.

10 El-Sakka AI, Hassoba HM. Age-related testosterone depletion in patients with erectile dysfunction. J Urol 2006; 176: 2589-93.

11 Rosen RC, Riley A, Wagner G, Osterloh IH, Kirkpatrick J et al. The International Index of Erectile Function (IIEF): a multidimensional scale for assessment of erectile dysfunction. Urology 1997; 49: 822-30.

12 Quek KF, Low WY, Razack AH, Chua CB, Loh CS. Reliability and validity of the Malay version of the International Index of Erectile Function (IIEF-15) in the Malaysian population. Int J Impo Res 2002; 14: 310-5.
13 Wiltink J, Hauck EW, Phädayanon M, Weidner W, Beutel ME. Validation of the German version of the International Index of Erectile Function (IIEF) in patients with erectile dysfunction, Peyronie's disease and controls. Int J Impo Res 2003; 15: 192-7.

14 Feldman HA, Goldstein I, Hatzichristou DG, Krane RJ, McKinlay JB. Impotence and its medical and psychosocial correlates: results of the Massachusetts Male Aging Study. J Urol 1994; 151: 54-61.

15 Morales A, Buvat J, Gooren LJ, Guay AT, Kaufman JM et al. Endocrine aspects of sexual dysfunction in men. J Sex Med 2004; 1: 69-81.

16 Rochira V, Granata AR, Madeo B, Zirilli L, Rossi G et al. Estrogens in males: what have we learned in the last 10 years? Asian J Androl 2005; 7: 3-20.

17 Srilatha B. Adaikan PG. Estrogen and phytoestrogen predispose to erectile dysfunction: do ER-alpha and ER-beta in the cavernosum play a role? Urology 2004; 63: 382-6.

18 Miller G. Endocrinology: divorcing estrogen bright and dark sides. Science 2002; 298 : 723-4.

19 Oettel M. Is there a role for estrogens in the maintenance of men's health? Aging Male 2002; 5: 248-57.

20 O'Connor DB, Lee DM, Corona G, Forti G, Tajar A et al. The relationships between sex hormones and sexual function in middle-aged and older European men. J Clin Endocrinol Metab 2011; 96: E1577-87.

21 Huhtaniemi IT, Pye SR, Limer KL, Thomson W, O'Neill TW et al. European Male Ageing Study Group. Increased estrogen rather than decreased androgen action is associated with longer androgen receptor CAG repeats. J Clin Endocrinol Metab 2009; 94: 277-84.

22 Saltiki K, Papageorgiou G, Voidonikola P, Mantzou E, Xiromeritis K et al. Endogenous estrogen levels are associated with endothelial function in males independently of lipid levels. Endocrine 2010; 37: 329-35.

23 Srilatha B, Adaikan PG. Endocrine milieu and erectile dysfunction: is oestradioltestosterone imbalance, a risk factor in the elderly? Asian J Androl2011: 13: 569-73.

24 Burnett AL. Metabolic syndrome, endothelial dysfunction, and erectile dysfunction: association and management. Curr Urol Rep 2005; 6: 470-5.

25 Lin HY, Xu Q, Yeh S, Wang RS, Sparks JD et al. Insulin and leptin resistance with hyperleptinemia in mice lacking androgen receptor. Diabetes 2005; 54: 1717-25.

26 Rohrmann S, Shiels MS, Lopez DS, Rifai N, Nelson WG et al. Body fatness and sex steroid hormone concentrations in US men: results from NHANES III. Cancer Causes Control 2011; 22: 1141-51.

27 Dhindsa S, Furlanetto R, Vora M, Ghanim H, Chaudhuri A et al. Low estradiol concentrations in men with subnormal testosterone concentrations and type 2 diabetes. Diabetes Care 2011; 34: 1854-9.

28 Cohen PG. The role of estradiol in the maintenance of secondary hypogonadism in males in erectile dysfunction. Med Hypotheses 1998; 50: 331-3.

29 Kacker R, Traish AM, Morgentaler A. Estrogens in men: clinical implications for sexual function and the treatment of testosterone deficiency. J Sex Med 2012; 9: 1681-96.

30 Guay AT, Jacobson J, Perez JB, Hodge MB, Velasquez E. Clomiphene increases free testosterone levels in men with both secondary hypogonadism and erectile dysfunction: who does and does not benefit? Int J Impot Res 2003; 15: 156-65.

31 Leder BZ, Rohrer JL, Rubin SD, Gallo J, Longcope C. Effects of aromatase inhibition in elderly men with low or borderline-low serum testosterone levels. J Clin Endocrinol Metab 2004; 89: 1174-80.

32 Wang C, Catlin DH, Demers LM, Starcevic B, Swerdloff RS. Measurement of total serum testosterone in adult men: comparison of current laboratory methods versus liquid chromatography-tandem mass spectrometry. J Clin Endocrinol Metab 2004; 89: $534-43$. 